\title{
Arnauld's Verbal Distinction between Ideas and Perceptions
}

\author{
Kenneth L. Pearce \\ Valparaiso University
}

\begin{abstract}
In his dispute with Malebranche about the nature of ideas, Arnauld endorses a form of direct realism. This appears to conflict with views put forward by Arnauld and his collaborators in the Port-Royal Grammar and Logic where ideas are treated as objects in the mind. This tension can be resolved by a careful examination of Arnauld's remarks on the semantics of 'perception' and 'idea' in light of the Port-Royal theory of language. This examination leads to the conclusion that Arnauld's ideas really are objects in the mind, and not perceptual acts as many commentators hold. What Arnauld denies is that these mental objects are really distinct from the external objects they represent. Instead, Arnauld holds that, by the act of conception, the external objects themselves - not copies - come to be present in the mind and are therefore called 'ideas'.
\end{abstract}

Antoine Arnauld's On True and False Ideas is an attack on Nicolas Malebranche's theory of ideas as 'representative beings,' i.e., as entities "actually distinct from our mind as well as from the [external] object" (TFI, 63) ${ }^{1}$ by perception of which we (indirectly) perceive external objects. In this dispute Arnauld argues that, in a perceptual act, the mind is related directly to an external object without any sort of representational intermediary. However,

1. Primary sources are cited according to the following abbreviations:

Grammar Arnauld, Antoine, and Claude Lancelot. 1660. General and Rational Grammar: The Port-Royal Grammar. Edited and translated by Jacques Rieux and Bernard E. Rollin. Janua Linguarum. The Hague: Mouton, 1975. French edition: Grammaire Générale et Raisonnée. Paris: Prault Fils L'Aîné, 1754.

Logic Arnauld, Antoine, and Pierre Nicole. 1662. Logic or the Art of Thinking: Containing besides common rules, several new observations appropriate for forming judgments. Edited and translated by Jill Vance Buroker. Cambridge Texts in the History of Philosophy. Cambridge: Cambridge University Press, 1996. French edition: La Logique ou L'Art de Penser. 2nd ed. Edited by Pierre Claire and François Girbal. Textes Philosophiques. Paris: J. Vrin, 2012.

TFI Arnauld, Antoine. 1683. On True and False Ideas. Translated by Stephen Gaukroger. Classics of Philosophy and Science. Manchester: Manchester University Press, 1990. French edition: Des Vraies et Des Fausses Idées. In Euvres Philosophiques de Antoine Arnauld, edited by Jules Simon, 25-264. Paris: Adolphe Delahays, 1843.

The version of record for this paper appears in History and Philosophy of Logic 37 (2016): 375-390, http://dx.doi.org/10.1080/01445340.2016.1177440. Page references to that version are provided in the margin. 
despite Arnauld's rejection of representational intermediaries, he continues to speak of ideas. It is widely held that Arnauld means to identify these ideas with the perceptual acts whereby external objects are apprehended. ${ }^{2}$

This interpretation faces a serious, and hitherto unrecognized, ${ }^{3}$ problem. In the earlier Port-Royal Grammar and Logic, Arnauld and his collaborators propounded a theory of mental and linguistic representation that relied crucially on a distinction between objects in the mind (ideas) and mental actions performed on those objects.

Monte Cook long ago argued that, in On True and False Ideas, Arnauld allows only a "verbal distinction between ideas and perceptions" (Cook 1974, 62). I agree. My task in this paper will be to examine the nature of this verbal distinction and show that it is strong enough to meet the needs of the PortRoyal semantic theory and, more generally, to account for the various claims about ideas in the Grammar and Logic. The key to this reconciliation is the recognition that there is an important sense in which Arnauld's ideas are objects after all: the most direct signification of the word 'idea' is the external object (e.g., the real sun in the sky). This object is rightly called an 'idea' insofar as it has come to be in the mind by an act of conceiving. Thus Arnauld does hold that ideas are objects in the mind. The reason Arnauld's ideas are not objectionable intermediary entities is that they are not really distinct from the external objects they represent.

\section{Ideas in the Port-Royal Theory of Language}

The foundational assumption of the Port-Royal theory of language, what Martine Pécharman calls its 'anthropological hypothesis' (Pécharman 1995, 72), is that human beings are incapable of direct perception of the contents of other minds. To remedy this inconvenience, we have invented "the art of speaking," that is, of "explaining one's thoughts [to others] by signs which men have invented for the purpose" (Grammar, 41). These signs are words, and their purpose is "to indicate what takes place in the mind" of the speaker (Logic, $74)$.

From this foundational assumption, Arnauld and his collaborators construct a sophisticated theory of the structure of mental and linguistic representation. Insofar as words serve their purpose of indicating what takes place in the mind,

2. This sort of act theory of ideas is attributed to Arnauld by Cook 1974; Radner 1976; Nadler 1989; Watson 1994; and Kremer 1994a. Yolton 1975 adopts an interpretation closer to the one I will be defending. Hoffman 2002 and Van Cleve 2015 deny that Arnauld is a direct realist at all.

3. None of the sources cited in the previous note address the compatibility of On True and False Ideas with the Grammar and Logic. Kambouchner 1995, 178-190 does discuss, at some length, certain problems in harmonizing the talk of ideas in the Logic with the thesis of On True and False Ideas. However, Kambouchner arrives at the conclusion that Arnauld's ideas are Husserlian intentional objects, distinct from perceptions and external objects but lacking any formal reality of their own (188-189). This interpretation is extremely difficult to reconcile with Arnauld's insistence that ideas need efficient causes (see below, §6) and also fails to take seriously Arnauld's identification of ideas with perceptions. 
the Port-Royalists hold, the structure of language must mirror the structure of the mind. ${ }^{4}$

The central element of this structure is the grammatical distinction between nouns and verbs which mirrors the distinction between the mental operations of conceiving and judging. ${ }^{5}$ 'Conceiving' is defined as "[t]he simple view we have of things that present themselves to the mind" (Logic, 23). 'Judging' is defined as "the action in which the mind, bringing together different ideas, affirms of one that it is the other, or denies of one that it is the other" (23). Accordingly, nouns are said to signify "the objects of thought," while verbs signify "the form and the manner or mode of our thoughts" (Grammar, 67-68). ${ }^{6}$

The first part of the Logic has the title "Containing reflections on ideas, or the first action of the mind, which is called conceiving." It begins with the affirmation that "we can have no knowledge of what is outside us except by means of the ideas in us" (Logic, 25). Later on, the authors describe this first action or operation of the mind as "conceiving things by our ideas" (82).

The Port-Royalists' official position is that "[t]he word 'idea' is one of those that are so clear that they cannot be explained by others, because none is more clear and simple" (25). However, they do make two remarks that sound very much like definitions of 'idea'. First, they write that "the form by which we represent ...things is called an idea" (23). Second, they write, "[w]hen we speak of ideas ... we are ... referring ...to anything in the mind when we can truthfully say that we are conceiving something" (26). The idea, then, is an object in the mind which serves as the instrument by means of which the act of conception allows us to represent to ourselves the external object. Nouns immediately signify these internal, immediate objects of thought and mediately signify the external objects thereby represented to the mind.

This account of ideas as objects is reinforced by the Port-Royal theory of the verb. The verb is defined as "a word whose principal use is to signify affirmation" (Grammar, $122=$ Logic, 79$){ }^{7}$ As the authors carefully explain, unlike the noun 'affirmation', the verb does not signify the speaker's idea of affirmation, but rather the speaker's act of affirming (Grammar, 122-123= Logic, 79). ${ }^{8}$ The simplest verb, which signifies only the act of affirmation, is the copula. Thus in the sentence 'Peter is alive,' 'Peter' signifies Peter, 'alive' signifies being alive, and 'is' signifies the act of affirmation whereby the speaker

4. Cf. Buroker 2014, §2: "language can signify thought insofar as the structure of a linguistic expression mirrors the structure of the ideas it expresses."

5. On the centrality of this distinction to the Port-Royal theory, see Pécharman 1995, 82-83, et passim.

6. In addition to nouns, articles, pronouns, prepositions, and adverbs are associated with conceiving. In addition to verbs, conjunctions and interjections are associated with the manner of thought (Grammar, 68). These additional complexities will not be important for purposes of this paper.

7. The Grammar's chapter on the verb was reproduced in the Logic (Grammar, 122-128; Logic, 78-82). When referencing this chapter, I give both citations, joined by an '=' sign.

8. In this paper, I use quote-names to refer to linguistic items (words, phrases, sentences, etc.) and italics to refer to psychological items (ideas, judgments, etc.). In contexts where this does not introduce confusing ambiguities, italics are also used for emphasis. 
Arnauld's Verbal Distinction between Ideas and Perceptions

puts these ideas together in order to regard Peter as being alive. ${ }^{9}$ Whereas the copula signifies the act of affirming alone, other finite verbs signify acts of affirming particular ideas. For instance, 'lives' signifies the act of affirming being alive, so that the sentence 'Peter lives' is merely an abbreviation of 'Peter is alive' in which the predicate idea is built in to the verb (Grammar, $123=$ Logic, 79).

This is the basic contrast between the noun as signifying the object of thought and the verb as signifying the manner or mode of thought. The manner of thought is the way in which the objects of thought are put together in order to form a truth-evaluable proposition (82). This can happen only after the act of conception has made objects available to us "by means of our ideas" (25). In this way, the Port-Royal theory appears to rely crucially on a conception of ideas as objects.

\section{Idea-Perceptions in On True and False Ideas}

In On True and False Ideas, Arnauld argues that believers in ideas as 'representative beings' have been led into error by stretching too far the metaphor of seeing things 'with the mind's eye.' In particular, these philosophers hold that "for the mind just as for the eyes, the object must be present if it is to be seen" (TFI, 59). However, the mind is spiritual and is not physically located, so the 'presence' in question cannot be physical (cf. Malebranche 16741675, 219; quoted at TFI, 64). Thus, these philosophers conclude, "bodies can be present to [the mind] only through particular representations called ideas or species which, being similar to them, take their place and are in immediate contact with the soul" (TFI, 62). As the use of the term 'species' indicates, Arnauld is here thinking primarily of the Aristotelian theory of perception on which the active intellect produces the (immaterial) 'intelligible species' by 'spiritualizing' the (material) 'sensible species' received by the sense organs (61-62). However, Arnauld's target in this work is Malebranche, who shares Arnauld's Augustinian-Cartesian orientation, and hence sees the Scholastic doctrine as violating the radical distinctness of the material and the mental (spiritual). For these Augustinian-Cartesian philosophers, the notion of anything material being 'spiritualized' is absurd.

The reason Arnauld takes this detour through Aristotelianism is that he believes Malebranche has not sufficiently broken free from the Aristotelian paradigm and so is taking positions inconsistent with their shared Augustinian-Cartesian commitments. Arnauld rightly observes that Malebranche attacks the Aristotelian approach and is committed to the view "that the comparison of corporeal with spiritual vision ... is false in every respect" (TFI, 62; see, e.g., Malebranche 1674-1675, 220-221). ${ }^{10}$ Nevertheless, according to Arnauld, it is

9. I follow Buroker 1993, 1996; 2014, §3.1; Schaar 2008; and Marušić 2014 (against Ott 2002) in taking the act of affirmation to have assertive force.

10. Perhaps in response to Arnauld's criticism, Malebranche puts much stronger emphasis on the difference between corporeal vision and spiritual perception in his later Dialogues on 
precisely this false comparison that leads Malebranche to regard direct perception of (e.g.) stars as implying "that the soul should leave the body to stroll about the heavens, as it were, in order to behold all these objects" (Malebranche 1674-1675, 217; quoted at TFI, 63). This presence requirement comes from a supposed analogy with corporeal vision, but Malebranche knows perfectly well that corporeal vision does not require presence (we can perceive distant stars) and that spiritual perception is in no way analogous to corporeal vision (cf. Nadler 1989, 91-95).

According to Arnauld, the presence requirement, together with the impossibility of a material thing being present to a spiritual thing, is what leads Malebranche to conclude that we must immediately perceive only 'spiritual' ideas and not external material objects. Arnauld argues that this strategy runs off the rails from the very beginning by trying to explain what stands in no need of explanation. Arnauld alleges that Malebranche "has failed to follow the rules of reasoning which he rightly prescribes to others" (TFI, 50). One of these rules is

not to seek reasons ad infinitum, but to stop when we get to what we know to be the nature of a thing, or what we know with certainty to be a quality of it. One must not ask why extension is divisible, for example, or why the mind is capable of thought, for it is the nature of extension to be divisible, and that of the mind to think. ${ }^{11}$

Furthermore, "just as it is clear that $I$ think, it is also clear that I think of something, i.e. that I know and perceive something. For that is what thought is essentially" (53). Arnauld's view is that the essence or nature of thought is to represent (Nadler 1989, 126-127, 177-178). According to Arnauld's rule, when we have identified the nature of a thing, we have reached the point where explanation comes to an end: the mind thinks because its nature is to think, and thoughts represent because their nature is to represent, and this is as far as explanation can, or should, go.

In drawing this conclusion Arnauld asserts, "it is ridiculous to ask how it comes about that our mind perceives objects" (TFI, 54). However, he is careful to clarify that he is not dismissing the efficient causal questions, "why my mind exists" (53) and "what is the cause of our thinking of one object at one time and another at another time" (54). Rather, Arnauld uses his rule to dismiss any further formal causal questions: "when one has come to know the nature of a thing, there is no longer anything, by way of formal causes, left to seek" (53; cf. 152-155). Arnauld makes this point not only with regard to the soul itself, but also with regard to its modes - i.e., its perceptual acts: "as regards the formal cause of our perceptions of objects, there is no question to be asked" (54). One can indeed ask for an efficient cause of my perceiving (e.g.) red rather than yellow, but Arnauld rejects as ill-posed the formal causal question, what

Metaphysics and on Religion (Malebranche 1688, 1-18, 57-59).

11. TFI, 50. The question of which propositions do and do not require proofs is discussed at greater length at Logic, 246-252. 
is it about this perception that makes it of red rather than yellow? As I can observe in introspection, my perception just is a perception of red rather than yellow. For Arnauld, the representative capacity of thought must be taken as primitive. $^{12}$

Embedded in this discussion is the following argument for the conclusion that ideas are modes of the mind and not Platonic objects as Malebranche thought (TFI, 53):

true modifications cannot be conceived without conceiving of the substance of which they are the modifications; so if it is my nature to think, and I can think of different things without changing my nature then these different thoughts can only be different modifications of the thinking which constitutes my nature.

Arnauld connects his view with Descartes's definition of an idea as "that form of any given thought, immediate perception of which makes me aware of the thought" (Descartes 1984-1991, 2:113). Arnauld glosses this as the claim that the idea "is not really distinct from our thought or perception, but is rather our thought itself insofar as it contains objectively what is formally in the object" (TFI, 72-73). In other words, what idea I am having is just a matter of what sort of perceptual act I am performing. Arnauld (and, on Arnauld's interpretation, Descartes $)^{13}$ can thus be seen as what we would now call an adverbialist: he holds that to have a particular idea is to perceive or think in a certain manner. For instance, to have the idea of red is to perceive redly.

In Arnauld's view, when I perceive (or imagine, or think of) something red, and thus may be truly said to have (occurrently) an idea of red, my soul undergoes a certain modification - the modification I have just called 'perceiving redly'. ${ }^{14}$ This modification just is a single mental state, and which sort of state it is is entirely a matter of its intrinsic nature; it does not depend on a relation to another mental state, a Platonic entity, or a concrete object to get its nature. However, if this is to be an account of mental representation, it must be the case that agents who exemplify such a mental state are (at least sometimes) thereby related to objects in the world. This relation Arnauld takes as primitive. It

12. Cf. Radner 1976, 98; Nadler 1989, 174; Cook 1994, 73; Watson 1994, 268-270.

13. For defenses of Arnauld's interpretation of Descartes, see Yolton 1975; Nuchelmans 1983, §2.1; Cook 1987; Nadler 1989, §15. For a contrary view, see Wells 1994, 1999.

14. Sara García-Gómez holds instead that the perceiving causes the modification of the soul. She writes, "Arnauld seems to suggest that the perception-idea is responsible for causing the modification of the soul, for he speaks of its relation 'á l'âme qu'elle modifie"' (García-Gómez 1988, 544, quoting TFI, 66). As García-Gómez clearly sees, this leads to a number of puzzles regarding Arnauld's insistence on the unity of the idea-perception. Although the French verb 'modifier' does often mean 'to cause a change in something,' in Cartesian jargon a modification is said to modify its subject. This is not to assert that the modification causes a change in its subject, but only that the modification is a way the subject is. In other words, what Arnauld says here is not that the perception is related to the mind in which it causes some change, but rather that the perception is related to the mind that is doing the perceiving. This is supported by the example Arnauld uses to explain this relation: "the perception of a square has as its most direct meaning my soul perceiving the square" (66). There can be no perception without a mind that does the perceiving. 
is entirely in virtue of the intrinsic nature of my mental act that I count as perceiving red; no object distinct from that act plays any role in constituting its content (cf. Nuchelmans 1983, 72; Nadler 1989, 167-170).

We can summarize Arnauld's theory of mental representation as follows. In every perceptual event, there is involved a particular act of perception, which is a modification of some mind. This modification must be of a particular sort, which is to say that it must have a particular form. It is regarding this form that Arnauld is a primitivist: he holds that it is the nature of a given perceptual act to have a certain content and no more can be said about the matter. Certainly no reductive analysis of what it is for a perceptual act to have this or that content can be given; it is simply a brute fact that such an act of perception has such a content. A perception is of an external object when that object matches the content.

Arnauld denies the existence of any 'mental' or 'spiritual' object of perception mediating our contact with the external world. The only objects of perception are the external objects. However, the Port-Royal theory of language requires that among the things in the mind, which alone are eligible to be signified immediately, there must be objects as well as acts. The thesis of On True and False Ideas is that there are no such objects.

\section{$3 \quad$ Ideas as Acts of Conceiving?}

One rather obvious way of resolving this apparent contradiction would be to identify the idea with the act of conceiving. Arnauld follows Descartes in using the word 'perception' extremely broadly: "[t]o think, to know, and to perceive are the same thing" (TFI, 65). Accordingly, conceiving and judging, as well as all other mental operations, will be among the varieties of perception.

The identification of ideas with acts of conceiving is supported by the fact that, in initially introducing the act of conception and the idea, the Logic calls the idea "the form by which we represent ...things" in our acts of conception (Logic, 23, emphasis added). This, as we have seen, is the same language used in On True and False Ideas.

This interpretation is partly correct. Most importantly, in On True and False Ideas, Arnauld frequently identifies ideas with perceptions and the perceptions he is talking about here clearly must be the kind of perceptual acts the Grammar and Logic call acts of conceiving. However, a straightforward identification of ideas with such acts will not make sense of all the things Arnauld and his collaborators say about ideas and acts of conceiving.

First, what does it mean to say that the idea is the form of the thought, perception, or conception? Second, why are ideas repeatedly described as the objects of thought, in contrast to acts of judging which are manners or modes of thought? Third, why are ideas treated as instruments by means of which the act of conceiving makes external objects available to thought?

Each of these ways of talking about ideas seems to militate against the view that ideas just are perceptions. As it turns out, Arnauld does not intend a 
Arnauld's Verbal Distinction between Ideas and Perceptions

straightforward identification of ideas with perceptions, for he explicitly draws a semantic distinction between 'perception' and 'idea'. Careful examination of this semantic distinction in light of the Port-Royal theory of language will help us to resolve these quandaries and achieve a proper understanding of the relationship between perceptions and ideas.

\section{Arnauld's Analysis of 'Perception' and 'Idea'}

According to Arnauld, two things must happen in all thought: there must be a soul which is the subject of a modification, and that modification must be representative in nature (must have some content). To speak of perceiving and to speak of having ideas are two different ways of describing this situation. Yet these two descriptions genuinely differ in meaning. 'Perception' and 'idea,' Arnauld says, refer to "a single modification of our soul which necessarily contains [two] relations:" it is related to the soul which perceives, and to the object which is perceived. The use of 'perception' emphasizes the former relation, and the use of 'idea' emphasizes the latter, but both words refer to the same modification (TFI, 66; cf. Cook 1974, 55-56).

Arnauld describes the difference in meaning between 'perception' and 'idea' as a difference in the 'most direct' meaning or reference of the words (TFI, 66). The contrast between more and less direct meanings (significations) is drawn from the Port-Royal theory of adjectives. Adjectives are defined as words "that signify manners, indicating at the same time the subject to which they apply" (Logic, 74). Such words

have essentially two significations: one distinct, which is the signification of the mode or manner, the other confused which is that of the subject. But although the signification of the mode is more distinct, it is nonetheless indirect; and by contrast, that of the subject, although confused, is direct. The word 'white,' candidum, signifies the subject directly but confusedly, and whiteness indirectly but distinctly. ${ }^{15}$

The claim that adjectives directly signify the subject of the modification is supposed to explain the contrast between an adjective and its corresponding abstract noun (e.g., between 'wise' and 'wisdom'). In a sentence like 'Socrates is wise,' the role of the word 'wise' is to signify the manner in which Socrates is conceived. For this reason it here refers 'most directly' to Socrates. Similarly, in a sentence like 'rebuke a wise man, and he will love thee' (Proverbs 9:8), the word 'wise' helps to identify which men (people) the speaker has in mind. This is in contrast to 'wisdom is a virtue' in which the mode (wisdom) is "conceived by mental abstraction, without being referred to a particular subject" (74). The adjective, unlike the corresponding abstract noun, signifies wisdom only insofar as it is possessed by some person or persons. This person or these persons is/are signified directly and wisdom indirectly.

15. Logic, 74-75; cf. Grammar, 72. 
Nevertheless, the Logic tells us, the indirect signification is more distinct than the direct signification. Thus, "Album [white], ${ }^{16}$ for example, signifies a thing that has whiteness, which determines the confused idea of a thing to represent only those things having this quality" (Logic, 46).

The notion of confused signification in place here is clarified in the Logic's discussion of 'equivocation by error'. Equivocation by error occurs when a descriptive phrase is used to pick out some one particular thing but, because of disagreement about the facts, speakers disagree regarding which thing it picks out. For instance (46):

the words 'true religion' signify but a single and unique religion ... But because each nation and each sect believes that its religion is the true religion, these words are highly equivocal ... If we read in a history book that a prince was zealous about the true religion, we could not know what was meant unless we knew the historian's religion.

On the other hand, "The words 'true religion' are not at all equivocal as long as they are joined to a confused idea, and not to the distinct idea of any particular religion, since they signify only what is in fact the true religion" (47).

Here we have a distinction between two ways of using the words "true religion'. On the one hand, Arnauld could use that phrase as a synonym of 'Roman Catholicism'. As long as he spoke only to other Catholics, this would cause no difficulties, but of course this usage would be extremely problematic in conversation with a Protestant or Muslim, since one's conversation partner would associate 'true religion' with a completely different idea. On the other hand, if 'true religion' is used to mean 'that religion, whichever it is, which is in fact true', then adherents of all religions can associate the phrase with the same idea, and so communicate successfully. In the former usage, 'true religion' is distinct, but equivocal in signification. That is, in the mouth of each individual speaker, its semantic content precisely determines some particular object of which the speaker has an idea containing a great deal of information, but different speakers associate different distinct ideas with the phrase, leading to communication failure. In the latter usage, 'true religion' is univocal, but confused. That is, everyone means the same thing by it, but its semantic content is too impoverished to give us any kind of detailed conception of what we are talking about. Thus, for instance, on the former usage but not on the latter, the meaning of 'true religion' settles the question of whether the true religion includes belief in transubstantiation. It is precisely the fact that the latter usage does not foreclose this question as a matter of meaning that makes it the useful one in inter-faith dialogue. ${ }^{17}$

Returning to adjectives, we can now see that what is confused about them is that they give us only a very impoverished conception of the subject which

16. Translator's insertion.

17. For detailed discussion of the Logic's theory of equivocation by error, see Stoianovici 1976; Pariente 19956. 
they directly signify, since they allow us to conceive only a single mode of that subject. On the other hand, an adjective like 'round' gives us a perfectly adequate conception of roundness, the mode it indirectly signifies.

In applying this distinction to 'idea' and 'perception', Arnauld suggests that semantically, although of course not syntactically, those words are adjectives. This is not surprising, since, as we have seen, Arnauld holds that, metaphysically, the idea-perception is a mode of the mind. The difference between 'idea' and 'perception' is in the subject which is directly signified. 'Idea' functions like an adjectival use of 'conceived' (e.g., 'conceived square'), while 'perception' functions like an adjectival use of 'perceiving' (e.g., 'perceiving mind'). Like 'conceived' in the phrase 'conceived square', 'idea' in 'idea of a square' signifies the square directly but confusedly, since it doesn't tell us anything about the square other than that it is conceived. The property of being conceived is, on the other hand, signified distinctly but indirectly. Like 'perceiving' in the phrase 'perceiving mind,' 'perception' signifies the mind directly but confusedly and the property of perceiving distinctly but indirectly. The crucial upshot for our purposes is that, just as 'sitting' in 'Socrates sitting' signifies Socrates insofar as he possesses a certain property (being seated), so 'perception' signifies the mind insofar as it possesses a certain property (perceiving) and 'idea' signifies the external object insofar as it possesses a certain property (being perceived).

This theory of Arnauld's is supposed, as we have already seen, to be an elaboration on Descartes's statement that an idea is a form of thought. Earlier, I argued that, given how Arnauld understands this statement, he should be classified as having an adverbial theory of mental contents, that is, as taking the different contents perceptions can have as being characteristics of the perceptual act. However, Arnauld's emphasis on the connection between the idea and the external object - defining 'the idea of a square' as "the square in so far as it is objectively in my mind" (TFI, 66) - muddies the waters somewhat. Fortunately, not long after his discussion of the meanings of 'idea' and 'perception,' Arnauld offers a clarification of this issue (67; cf. 89-90):

We must not confuse the idea of an object with that object conceived, at least as long as one does not add 'insofar as it is objectively in the mind'. For being conceived, in regard to the sun that is in the sky, is only an extrinsic denomination, i.e. only a relation to the perception which I have of it.

The Logic defines an 'extrinsic denomination' as a mode "taken from something that is not in the substance, such as 'loved,' 'seen,' 'desired,' names derived from the actions of something else" (Logic, 32).

The theory of extrinsic denominations explains how Arnauld can simultaneously identify the idea with the external object and insist that the idea is a mode of the mind. Just as John is entitled to to be called 'loved' on account of Mary's love for him (a mode of Mary's mind), so the sun is entitled to be called 'idea' on account of my conceiving of the sun (a mode of my mind). This mode - i.e., the form of my thought - is the indirect, but more distinct, signification of 'idea of the sun'. The sun itself (the one in the sky) is the direct, but more 
confused, signification. This also explains the sense in which the perception and the idea are identical: just as one and the same worldly state of affairs entitles Mary to the (intrinsic) denomination 'lover' and John to the (extrinsic) denomination 'beloved', so one and the same worldly state of affairs entitles my mind to the (intrinsic) denomination 'perception' and the sun to the (extrinsic) denomination 'idea'. The mode of my mind in virtue of which these labels apply is the indirect, distinct signification shared by both words.

Since 'idea' is an extrinsic denomination of the sun, the change from being perceived to not being perceived does not require any change in the intrinsic features of the sun. Whether I perceive the sun or not is entirely a matter of the intrinsic features of my mind (cf. Nadler 1989, 126-127, 146, 167-168, 177-178). This is also the reason why it is possible to perceive an object that does not exist: being perceived does not require having any intrinsic features. ${ }^{18}$

When I speak of the 'idea of the sun,' I am talking about the actual sun, the one in the sky, but I am applying to it extrinsic denominations, predicates which are true of it not in virtue of its own intrinsic nature, but in virtue of the state of my mind. In saying that we must be careful to add the qualification 'insofar as it is objectively in my mind' when identifying my idea of the sun with the sun in the sky, Arnauld is not denying that the identity holds. Indeed, in this very passage he affirms it: "the idea of the sun is the sun itself, in so far as it is in my mind" (TFI, 67). ${ }^{19}$ Rather, he is trying to guard against the mistake of believing that the properties of my manner of representing the sun

18. "When I conceive of the sun, a square or a sound, then the sun, the square or the sound are objectively in my mind, whether or not they are external to my mind," i.e., whether or not they really exist (TFI, 66, emphasis added; cf. Logic, 32, 62; TFI, 86-87; for discussion see Cook 1974, 54-55; Radner 1976). On Arnauld's view, the phrase 'my idea of a unicorn' signifies unicorns as perceived by me, with the consequence that if 'unicorn' fails to refer, then so does 'my idea of a unicorn'. Nevertheless, since unicorns can be perceived by me even though they do not exist, I can truly be said to have an idea of a unicorn (i.e., to think of a unicorn), and my idea of a unicorn can truly be said to represent unicorns as white, magical, and elusive (i.e., I can be said to think of unicorns as having these features). Andrew Bacon has recently shown that it is possible to construct a logic and a formal semantics on which only some predicates are existence-entailing with the result that some sentences containing empty names are true while others are false (Bacon 2013). A logic and semantics with these features is required by Arnauld's theory of mind and language.

19. Van Cleve 2015 argues that the Latin text of Descartes's reply to Caterus, from which Arnauld draws this phrase, is ambiguous. Rather than meaning "the sun itself existing in the mind" Descartes might instead mean "that (second) sun which exists in the mind" (477). Now, it is true that there is nothing in Descartes's Latin equivalent to the phrase "in so far as it." Thus, as Van Cleve points out, there is no explicit reference back to the sun in the sky at that point in the sentence, nor is it clear exactly what the participle-phrase "existing in the intellect" ("in intellectu existens") is doing. However, Van Cleve's interpretation fails to attach any significance to the intensifying pronoun 'ipse' which Descartes attaches to 'sol'; if this does not mean the same sun, the one in the sky we were just talking about, then it is not clear what it does mean. Furthermore, the French text which Arnauld quotes is not ambiguous in this way. Arnauld's French reads, "le soleil mème, en tant qu'il est objectivement dans mon esprit." (The word 'objectivement' ['objectively'] is missing from Gaukroger's translation.) The phrase 'en tant que' unambiguously indicates that we are to consider the sun merely insofar as it is conceived by me. Van Cleve concedes this point, but denies that Arnauld can consistently adhere to the identity claim (478n17). The interpretation developed here shows that this is mistaken. 
are intrinsic properties of the sun. Thus, for instance, instead of saying "the sun appears small to me," I could say "my idea of the sun is small." This would not be to describe the intrinsic features of the sun, but rather to say how the sun is represented in my perception. That is, it would ascribe to the sun the feature, being represented as small (cf. Descartes 1984-1991, 2:27). But this is only an extrinsic denomination.

\section{$5 \quad$ Ideas as Instruments of Conception}

Of the three puzzles raised in $\S 3$, we have solved two. To speak of ideas is to speak of external objects insofar as they are conceived by us. Accordingly, ideas truly are the objects of thought, in contrast to acts or operations like judging. These objects are made available to the mind by acts of conceiving, and it is only insofar as this conceiving occurs that the objects are entitled to the name 'idea'. Although these objects, which are directly signified by the word 'idea', are not identical to acts of conceiving, the idea can be said to be the form of my thought because my having a thought with a particular form is the metaphysical reality in virtue of which the object is called 'idea'. This mode of my mind (my thought) is indirectly signified by 'idea' and also by 'perception'. Thus ideas and perceptions are the same thing in just the way that Mary's being a lover is the same thing as John's being loved: the labels 'lover' and 'loved' are applicable in virtue of the same mode, a mode which, metaphysically speaking, is possessed by Mary. Yet the one label is applied to Mary and the other to John.

One puzzle remains: why does the Logic repeatedly talk about ideas as if they were instruments by which the act of conceiving makes external objects available to thought? At one point, it is even claimed that knowledge of the world requires the mediation (French: 'l'entremise') of our ideas (Logic, 25). How can we be said to know objects by means of ideas, if the ideas are the objects themselves?

Although he does not use precisely the same language that is used in the Logic, this is clearly the same question that is at issue in chapter 6 of $O n$ True and False Ideas, where Arnauld explains how he interprets the expressions 'we do not see things immediately' and 'it is the ideas of them which are the immediate objects of our thought' (TFI, 70). According to Arnauld, these claims are trivial truths to which Malebranche has mistakenly given excessive metaphysical weight by misunderstanding the mediate/immediate contrast at issue. Here is how Arnauld explains the matter at the conclusion of the chapter (76-77):

But my principal aim in this chapter being to undo the equivocation in the word 'immediately', I declare here that if, by conceiving of the sun, a square or a cubed number immediately one understands this to be the opposite of conceiving them by means of ideas, such as I have defined these in the last chapter, i.e. as the same things as perceptions, then I agree we do not see them immediately, for nothing could be clearer than that we only see, perceive or know them by 
Arnauld's Verbal Distinction between Ideas and Perceptions

means of the perceptions that we have of them ... But if by not knowing them immediately one understands only the ability to know them through representations distinct from perceptions, I maintain that, in this sense, it is not only mediately but also immediately that we know not only God and our soul but material things also. That is to say, we can know them without any intermediary between our perceptions and the object.

To say that we conceive things only by means of our ideas is to say that we conceive them only by acts of conceiving. To deny this would be to claim that we can conceive them without conceiving them, and this is clearly absurd.

If, however, the claim that conception of objects requires the mediation of ideas is just this tautology (we can't conceive without conceiving), then the discussion of ideas and their importance in the Logic becomes extremely puzzling (cf. Kambouchner 1995, 179). The first sentence of the first part of the Logic reads: "As we can have no knowledge of what is outside us except by means of ideas in us, the reflections we can make on our ideas are perhaps the most important part of logic, since they are the foundation of everything else" (Logic, $25)$. The claim that we conceive things only by conceiving them fails to motivate this view of the foundational importance of ideas to the art of thinking.

Similarly, the Logic opens its discussion of the proposition by remarking that "[a]fter conceiving things by our ideas, we compare these ideas and, finding that some belong together and others do not, we unite or separate them" (82). If 'conceiving things by ideas' meant 'conceiving things by conceiving them,' then the mode of expression here would be unnecessarily convoluted. If this was their meaning, then Arnauld and Nicole should have written, "after conceiving things, we compare them and, finding that some belong together ..." A plausible interpretation of the Logic requires that this talk of ideas do some philosophical work. This is especially true in light of the fact that the Logic was intended to be understood by those who had not read On True and False Ideas, which was published more than twenty years after the first edition of the Logic.

Attention to the rest of chapter 6 makes clear that, although Arnauld holds these claims about the mediation of ideas to be trivial from the perspective of the metaphysics of mental representation, he does not take them to be tautological in meaning. Correctly understood, the principle that all thought is mediated by ideas is indeed foundational to the art of thinking.

Arnauld's clearest explanation is as follows:

[I]f I think of the sun, the objective reality of the sun, which is present to my mind, is the immediate object of this perception; and the possible or existing sun, which is outside my mind, is so to speak its mediate object ... it is true in this sense that, not only in the case of material things but generally in regard to all things, it is our ideas that we see immediately and which are the immediate object of our thought. This does not prevent us from also seeing, by means of these ideas, the object that contains formally what is only objectively in the idea; for example, my conceiving the formal being 
Arnauld's Verbal Distinction between Ideas and Perceptions

of a square which is objectively in the idea or perception that I have of a square. ${ }^{20}$

According to the definition given in chapter 5, "a thing is objectively in my mind when I conceive it. When I conceive of the sun, a square or a sound, then the sun, the square or the sound are objectively in my mind, whether or not they are external to my mind" (TFI, 66). In other words, what is objectively in the mind is just the content represented by the perceptual act.

The claim that we can only think of things by means of ideas amounts to the claim that we can only think of things by bringing those things into the mind objectively, i.e., by making those things part of the content of our thought. The object insofar as it is part of the content of my thought is immediately perceived while that same object insofar as it exists outside my thought can be said to be perceived only mediately, since my awareness of it depends on the act of conception whereby it is objectively present to my mind. Recognizing this fact does provide motivation for attributing foundational importance to reflections on ideas (i.e., on objects insofar as they are conceived) for purposes of the art of thinking because these objects are represented in our thoughts as possessing certain features. As we saw above, the features represented can come apart from the features actually possessed by the object. The subjects and predicates of propositions I form are objects-as-conceived-by-me. These propositions are the inputs to the operation of reasoning, which in turn provides the inputs to the operation of ordering. It is in this way that the study of ideas - that is, of objects-as-conceived - is foundational to logic: since thinking begins with conceiving, thinking well begins with conceiving well. To learn to conceive well, we must reflect on the manner in which conceiving brings objects into the mind and recognize this possibility for error: the object-as-conceived may possess different features from the object-as-external. (This is just to say that the object may be conceived to possess different features than it in fact possesses.) Thus the requirement for ideas as means of conceiving, which from the perspective of the metaphysics of perception is a triviality, is nevertheless foundational to the project of the Logic.

Monte Cook and Steven Nadler have both argued that Arnauld's motivation for attempting to preserve talk of ideas as intermediaries is to portray himself as a faithful follower of Descartes who also spoke in this way (Cook 1974, 58-60; Nadler 1989, 115-122). Recognizing that Arnauld needs to defend the use of these modes of expression in the Port-Royal Logic, and not simply their use by Descartes, makes far better sense of what happens in chapter 6 of On True and False Ideas (cf. Kambouchner 1995, 179).

Arnauld opens his discussion by claiming that, in order to understand these ways of talking about ideas, one must keep two points in mind: first, that every perception includes an implicit reflection on itself, which is just to say that

20. TFI, 71-72. Immediately before the quoted text, Gaukroger's translation erroneously has Arnauld saying that the perception "cannot be essentially reflective upon itself and its immediate object is not this idea," in direct contradiction to what Arnauld says in the rest of the chapter. A more adequate translation of the passage can be found in Nadler 1989, 116. 
"at the time I conceive [something] I know I conceive it" (TFI, 71). Second, there is such a thing as explicit reflection, whereby a second act of perception takes the first as its object. Arnauld then argues that reflection of this sort (whether implicit or explicit) presupposes that the act of perception already has a content. ${ }^{21}$

On Nadler's reading, Arnauld's case is already complete at this point: ideas (i.e., on Nadler's interpretation, perceptual acts) are the immediate objects of perception in that each idea-perception is implicitly reflective on itself. External objects can be perceived only by means of ideas because (tautologically) we cannot perceive them without perceiving, and ideas just are acts of perceiving. Nadler, however, leaves a crucial question unanswered: what is the point of the rest of the chapter?

In the remainder of chapter 6 , Arnauld gives a series of increasingly detailed examples of the role of reflection in reasoning. He says that, in doing this, he is clarifying his interpretation of talk about ideas as perceptual intermediaries (74). If, as Cook and Nadler suppose, Arnauld takes these ways of speaking to be utterly trivial, then it is not at all clear what the importance of reflection to reasoning has to do with ideas as perceptual intermediaries.

If, on the other hand, Arnauld's goal is to defend the motivation of Part 1 of the Port-Royal Logic, the structure of the chapter falls into place. According to Arnauld and Nicole, "[the] art [of thinking] does not consist in finding the means to perform [mental] operations, since nature alone furnishes them in giving us reason, but in reflecting on what nature makes us do" (Logic, 23). This reflection aims primarily at the practical goal of improving our thinking and recognizing errors in thinking, and secondarily at the theoretical goal of understanding the mind and its operations. The first part of the Logic invites us to reflect on our acts of conceiving, with special attention to the objects or contents of these acts. The authors also call this reflection on our ideas.

The Logic's talk about ideas as perceptual or cognitive intermediaries occurs in the course of explaining and motivating the project of Part 1, that is, in explaining why it is important to reflect on our acts of conceiving. According to Arnauld, it is precisely because conceiving is in one way transparent to the external object - it does not have a representational intermediary as its primary or immediate object - that we need to be reminded that our acts of conceiving can misfire, and to reflect on the situations in which they are and are not capable of error. Because what I conceive really is the sun in the sky, and not a Malebranchean representative being, I am prone to ignore the fact that the sun as I conceive it may not have precisely the same features as the sun as it really exists in the sky. One way of expressing this is to say that I do not perceive the sun immediately, but rather by mediation of my ideas.

In an ordinary (first-order) act of conceiving the sun, I explicitly attend only to the features of the sun, and I take the sun to be as I conceive it. I am aware only implicitly of the features of my act of conceiving. Asking whether

21. On the distinction between implicit (or 'virtual') and explicit (or 'express') reflection, see Nadler 1989, 118-122; Kambouchner 1995, 184-190. 
Arnauld's Verbal Distinction between Ideas and Perceptions

the sun really is as I conceive it to be requires explicit reflection on how I am conceiving the sun. This is the point of the distinction between implicit and explicit reflection: although implicit reflection is a pervasive feature of thought, explicit reflection is not, and explicit reflection is what is needed to improve our thinking by ensuring that we are conceiving correctly, as the first part of the Logic aims to do.

This explains why Arnauld proceeds, in chapter 6 of On True and False Ideas, to interpret and illustrate the use of the Cartesian maxim "everything that I clearly and distinctly perceive as being in the idea of a thing can be correctly asserted of that thing." This, note, is a rule about perceptions, and its application thus requires that we make explicit the reflection which is naturally implicit in all our perceptions (TFI, 73):

If, examining the idea that I have of a triangle (by reflecting on the perception that I have of it), I find that the equality of its three angles to two right angles is contained in this idea or perception, I can correctly assert that every triangle has three angles equal to two right angles.

There follows a more detailed illustration in which Arnauld explains how Thales might begin from the particular perceptions of twenty workers and twenty drachmas and, by various acts of reflection on the contents of his acts of conceiving, proceed to develop number theory (74-75).

What Arnauld is doing here is not just showing that he can accept certain manners of speaking which every good Cartesian must (in Arnauld's view) accept. Rather, he is explaining how the fact behind these ways of speaking the fact that we perceive things by acts of perceiving - can simultaneously be a metaphysical triviality and a foundational principle of the art of thinking.

\section{Objective Reality and Efficient Causation}

Arnauld trivializes ideas in two ways. First, he holds that our talk about ideas does not commit us to any metaphysics beyond minds and their actions. Second, he holds that the representational content (objective reality) of a thought is just a matter of what sort of thought it is and any further questions about formal causes (e.g., in virtue of what does this thought have this content?) are ill-posed. However, the needs of the Port-Royal Grammar and Logic prevent Arnauld from accepting any absolute trivialization of ideas. He is committed to the claim that a proper understanding of ideas, as objects of thought, is crucial to the art of thinking. There is also another factor preventing Arnauld from absolutely trivializing ideas. This is the question of the efficient causes of ideas.

We saw above that in rejecting formal causal questions about ideas Arnauld explicitly made room for efficient causal questions. There is an important reason for this. One of the key texts in which Descartes developed his account of objective reality, on which Arnauld is drawing in this discussion, is in his reply to Caterus' objections against the third meditation argument for the existence of 
God. This argument relied on the principle that "there must be at least as much $<$ reality $>^{22}$ in the efficient and total cause as there is in the effect" (Descartes 1984-1991, 2:28). In particular, it relied on the application of this principle to objective reality as well as formal reality. Caterus had attempted to undermine the argument by so trivializing ideas as to make the causal principle inapplicable to them. Arnauld accepts the third meditation argument and therefore insists that ideas need efficient causes (TFI, 54, 207-209). ${ }^{23}$

Caterus, like Arnauld, holds that 'idea' is an extrinsic denomination applied to external objects when those objects have objective being in the mind (Descartes 1984-1991, 2:66-67). According to Caterus, because a thing can come to have objective being in the mind "without any movement or change in the thing itself, and indeed without the thing in question existing at all" (2:67), there is no need to seek an efficient cause.

Caterus, however, has misunderstood the application of the theory of extrinsic denominations within Cartesian substance-mode ontology. An extrinsic denomination is a label which is applied to some object in virtue of a mode some other object possesses. In the case of 'idea', an object is entitled to this label in virtue of a mode of thinking possessed, not by the object labeled, but by some mind. Thus although no change takes place in an object when that object begins to be perceived (i.e., becomes an idea), nevertheless a real change takes place in the perceiving mind. This requires a cause. Thus Descartes says, "the precise question being raised is what is the cause of [the object's] being conceived" (2:75), and Arnauld says, "[t]he only legitimate question which could be asked about the cause of our perceptions is one concerned solely with the efficient cause of our contingent perceptions, namely, what is the cause of our thinking of one object at one time and of another at another time?" (TFI, 54). Arnauld's metaphysical trivialization of ideas does not threaten the legitimacy of this question.

Admittedly, Descartes appears to reject the extrinsic denomination interpretation of ideas when he writes, "if the question is about what the idea of the sun is, and we answer that it is the thing which is thought of, in so far as it has objective being in the intellect, no one will take this to be the sun itself with this extrinsic denomination applied to it" (Descartes 1984-1991, 2:75), ${ }^{24}$ and Arnauld claims to be following Descartes (TFI, 72-73). However, Arnauld is in a position to explain this remark of Descartes's. In this passage, Descartes distinguishes between two questions: the question, "what happens to the sun through its being objectively in my intellect" (Descartes 1984-1991, 2:74) and the question, "what the idea of the sun is" (2:75). To the former question, it is perfectly appropriate to reply "that nothing happens to [the sun] beyond the

22. Translators' insertion, based on the French translation.

23. This difficulty was brought to my attention by an anonymous referee. It is also mentioned briefly by Martin 2012, 71n23. Wells 1994, 1999 extensively discusses Descartes's reply to Caterus and its relevance to Arnauld, but does not raise the question of whether Arnauld might be veering dangerously close to Caterus here.

24. Cottingham, Stoothoff, and Murdoch translate the Latin phrase 'extrinseca denominatio' as 'extraneous label'. For terminological consistency I replace this with 'extrinsic denomination'. 
application of an extrinsic denomination to it." However, to give this answer to the second question would be to mistake its significance. The second question is about what it means to apply the label 'idea' to an object, or, in other words, what it takes for an object to qualify as an idea. ${ }^{25}$

For comparison, consider the extrinsic denomination 'aunt'. If one asks the question, 'what happens to a person when she becomes an aunt?' it is appropriate to answer that perhaps nothing at all happens to her. This is precisely what it means for 'aunt' to be an extrinsic denomination. But if, on the other hand, one asks the question, 'what is an aunt?' the answer 'a person to whom a certain extrinsic denomination applies' completely misses the point of the question. Furthermore, if one gives the correct answer, 'an aunt is a woman who has a niece or nephew', it would be incorrect to say that, since an aunt is therefore merely a person to whom a certain extrinsic denomination applies, no cause is needed in order for someone to become an aunt.

Descartes's reply to Caterus admits of a plausible reading which is consistent with Arnauld's theory. On this reading, the central point Descartes is making is that, just as, when someone becomes an aunt, although she may undergo no intrinsic change there is nonetheless a real change in the world which requires a cause, so also, when the sun becomes an idea, there is no intrinsic change in the sun but there is nevertheless a real change in the world which requires a cause. This change is a change in the perceiver. Accordingly, Caterus is incorrect to dismiss the question of what the idea of the sun is by the remark that 'idea' is only an extrinsic denomination. Furthermore Caterus is incorrect to suppose that because 'idea' is only an extrinsic denomination an idea requires no efficient cause. The understanding of ideas Arnauld endorses and attributes to Descartes does not so trivialize them as to undermine the third meditation argument.

\section{Conclusion: Arnauld on Mind and Language}

Arnauld's distinction between ideas and perceptions lacks metaphysical depth: according to Arnauld, the words 'idea' and 'perception' provide two different ways of talking about the same worldly states of affairs. The mode of the mind which is involved in that state of affairs is a perceptual or representational act, and this act is not mediated by any internal mental object. Nevertheless, the distinction between acts and ideas is sufficient for the uses to which it is put in the Port-Royal semantic theory. What the Port-Royal semantic theory requires is that there be objects of perception in the mind to function as the basic inputs to the mental operations which give rise to the structures of thought reflected in the structures of language. According to Arnauld's theory, these objects in the mind just are the external objects in the world. The act of conception brings the sun itself - the one in the sky, not a copy - into my mind "objectively" or "intelligibly" (TFI, 67), which is just to say that it makes the sun an object of my thought.

25. A similar reading of Descartes's reply to Caterus is advocated by Yolton 1975, 149-151. For an alternative reading, see Wells 1990. 
At the most general level, the Port-Royal theory of language says that, prior to the introduction of language, we have certain ideas, and we can perform certain operations on these ideas, by which complicated structures of thought can be constructed. The role of linguistic conventions is to attach arbitrary signs to our ideas and the more complex structures formed out of them. In On True and False Ideas, Arnauld argues that ideas are not mental objects distinct from our mental acts and the objects they are about. Arnauld denies that the idea is a distinct third term in perception not by identifying it with the perceptual act, but rather by identifying it with the external object conceived by me. My act of conceiving Peter makes Peter himself an idea - an object conceived by me. It does this without, of course, causing any change in Peter. Once these acts of conception make Peter and living objects of my thought, I am able to perform a further act whereby I (mentally) affirm living of Peter, which is to say, I judge that Peter lives. The sentence 'Peter lives' signifies this complex mental state. Contrary to appearances, the Port-Royal semantic theory does not require the introduction of the "representative beings" Arnauld abhors.

\section{Acknowledgments}

I thank James Van Cleve for many helpful discussions of this subject matter and for comments on a previous draft. I also thank Stephen Daniel and several anonymous referees for comments on previous drafts.

\section{References}

Bacon, Andrew. 2013. "Quantificational Logic and Empty Names." Philosophers' Imprint 13 (24).

Buroker, Jill Vance. 1993. "The Port-Royal Semantics of Terms." Synthese 96 (3): 455-475.

1996. "Arnauld on Judging and the Will." In Interpreting Arnauld, edited by Elmar J. Kremer, 3-12. Toronto: University of Toronto Press.

. 2014. "Port Royal Logic." In The Stanford Encyclopedia of Philosophy, Fall 2014 Edition, edited by Edward N. Zalta. http://plato. stanford. edu/archives/fall2014/entries/port-royal-logic/.

Cook, Monte. 1974. "Arnauld's Alleged Representationalism." Journal of the History of Philosophy 12 (1): 53-62.

1987. "Descartes' Alleged Representationalism." History of Philosophy Quarterly 4 (2): 179-195.

1994. "Malebranche and Arnauld: The Argument for Ideas." In Kremer 1994b, 69-88. 
Arnauld's Verbal Distinction between Ideas and Perceptions

Descartes, René. 1984-1991. The Philosophical Writings of Descartes. Translated by John Cottingham, Robert Stoothoff, Dugald Murdoch, and Anthony Kenny. 3 vols. Cambridge: Cambridge University Press.

García-Gómez, Sara F. 1988. "Arnauld's Theory of Ideative Knowledge: A Proto-Phenomenological Account." The Monist 71 (4): 543-559.

Hoffman, Paul. 2002. "Direct Realism, Intentionality, and the Objective Being of Ideas." Pacific Philosophical Quarterly 83 (2): 163-179.

Kambouchner, Denis. 1995. "Des Vraies et des Fausses Tenébrès: La Connaissance de l'Âme d'après la Controverse avec Malebranche." In Pariente 1995a, 153-190.

Kremer, Elmar J. 1994a. "Arnauld's Philosophical Notion of an Idea." In Kremer 1994b, 89-107.

ed. 1994b. The Great Arnauld and Some of His Philosophical Correspondents. Toronto: University of Toronto Press.

Malebranche, Nicolas. 1674-1675. The Search after Truth. Edited and translated by Thomas M. Lennon and Paul J. Olscamp. Cambridge Texts in the History of Philosophy. Cambridge: Cambridge University Press, 1997.

. 1688. Dialogues on Metaphysics and on Religion. Edited by Nicholas Jolley. Translated by David Scott. Cambridge Texts in the History of Philosophy. Cambridge: Cambridge University Press, 1997.

Martin, John N. 2012. "Existential Commitment and the Cartesian Semantics of the Port-Royal Logic." In The Square of Opposition: A General Framework for Cognition, edited by Jean-Yves Beziau and Gillman Payette. Bern: Peter Lang.

Marušić, Jennifer Smalligan. 2014. "Propositions and Judgments in Locke and Arnauld: A Monstrous and Unholy Union?" Journal of the History of Philosophy 52 (2): 255-280.

Nadler, Steven. 1989. Arnauld and the Cartesian Philosophy of Ideas. Studies in intellectual history and the history of philosophy. Princeton: Princeton University Press.

Nuchelmans, Gabriel. 1983. Judgment and Proposition: From Descartes to Kant. Amsterdam: North-Holland.

Ott, Walter. 2002. "Propositional Attitudes in Modern Philosophy." Dialogue 41 (3): 551-568.

Pariente, Jean-Claude, ed. 1995a. Antoine Arnauld: Philosophie du Langage et de la Connaissance. Histoire de la Philosophie. Paris: J. Vrin.

1995b. "Les Termes Singuliers à Port-Royal: Étude de Quelques Difficultés." In Pariente 1995a, 99-131. 
Pécharman, Martine. 1995. "La Signification dans la Philosophie du Langage d'Antoine Arnauld." In Pariente 1995a, 65-98.

Radner, Daisie. 1976. "Representationalism in Arnauld's Act Theory of Perception." Journal of the History of Philosophy 14 (1): 96-98.

Schaar, Maria van der. 2008. "Locke and Arnauld on Judgment and Proposition." History and Philosophy of Logic 29 (4): 327-341.

Stoianovici, Drăgan. 1976. "Definite Descriptions in Port-Royal Logic." Revue Roumain des Sciences Sociales, Philosophie et Logique, 20 (2): 145-154.

Van Cleve, James. 2015. "The Sun in the Sky and the Sun in My Mind: Or, Why Arnauld is not Steadfastly a Direct Realist." Appendix H to Problems From Reid. New York: Oxford University Press.

Watson, Richard A. 1994. "Malebranche and Arnauld on Ideas." The Modern Schoolman 71 (4): 259-270.

Wells, Norman J. 1990. "Objective Reality of Ideas in Descartes, Caterus, and Suárez." Journal of the History of Philosophy 28 (1): 33.

1994. "Objective Reality of Ideas in Arnauld, Descartes, and Suárez." In Kremer 1994b, 138-183.

_ 1999. "Jean DuHamel, The Cartesians, and Arnauld on Idea." The Modern Schoolman 76 (4): 245-271.

Yolton, John W. 1975. "Ideas and Knowledge in Seventeenth-Century Philosophy." Journal of the History of Philosophy 13 (2): 145-165. 